\title{
Grip Ability Test in Rheumatoid Arthritis Patients: Relationship With Disease Activity and Hand-Specific Self-Report Questionnaires
}

\author{
Çiğdem BİRCAN, ${ }^{1}$ Nihan ERDİNÇ GÜNDÜZ, ${ }^{1}$ Ayşegül TEKGÜL,,${ }^{1}$ Pınar ÇETİN, ${ }^{2}$ \\ Fatoş ÖNEN, ${ }^{2}$ Ramazan KIZIL, ${ }^{1}$ Selmin GÜLBAHAR ${ }^{1}$ \\ ${ }^{1}$ Department of Physical Medicine and Rehabilitation, Medical Faculty of Dokuz Eylül University, İzmir, Turkey \\ ${ }^{2}$ Division of Rheumatology, Department of Internal Medicine, Medical Faculty of Dokuz Eylül University, İzmir, Turkey
}

\begin{abstract}
Objectives: The aim of this study was to investigate the relationship between the Grip Ability Test (GAT) and disease activity, and hand-specific self-report questionnaires in patients with rheumatoid arthritis (RA).

Patients and methods: The study included 65 RA patients ( 55 females, 10 males; mean age $55 \pm 11$ years; range 24 to 74 years) who were diagnosed according to the American College of Rheumatology/European League Against Rheumatism 2010 criteria. Duration of disease and duration of morning stiffness were recorded. The number of tender and swollen joints and hand deformities were identified. A 100-mm visual analog scale (VAS) was used to assess the intensity of pain at rest and pain during activities of daily living, and stiffness. The grip strength was measured in both hands by a Jamar dynamometer. Flexion deficit in fingers II-V was recorded as the distance from the distal palmar crease to the tip of the fingers. The disease activity was measured with the Disease Activity Score 28. Health Assessment Questionnaire, hand and finger function subscale of Arthritis Impact Measurement Scale 2, and Duruoz Hand Index were completed by all patients.

Results: The mean duration of disease was $10.2 \pm 8.2$ years (range 1 to 42 years). Significant positive correlations were found between GAT score and duration of morning stiffness, VAS-pain during activities of daily living, VAS-stiffness, finger flexion deficit of dominant hand, Disease Activity Score 28, Health Assessment Questionnaire, Arthritis Impact Measurement Scale 2 hand/finger function subscale, and Duruoz Hand Index ( $r=0.261$ to $0.639, p<0.05)$. There were significant negative correlations between the GAT score and dominant $(r=-0.505, p<0.001)$ and non-dominant hand $(r=-0.399, p=0.001)$ grip strength. No significant correlation was found between the GAT and duration of disease, and VAS-pain at rest.

Conclusion: Weak to moderate correlations were found between the GAT and disease activity, and hand-specific self-report questionnaires in patients with RA. An evaluation of patients using a performance-based test such as GAT as well as clinical and laboratory assessments may provide important additional information about the patients' hand disability.

Key words: Grip ability test; hand disability; rheumatoid arthritis.
\end{abstract}

Rheumatoid arthritis (RA) is a chronic inflammatory disease with an unknown etiology which causes progressive joint damage. Clinical presentation may vary from mild, self-limiting arthritis to severe multisystem inflammation with extra-articular manifestations. Hand involvement is typically present in most of the patients and results in pain, swelling, limitation of motion, weakness, and deformity. These impairments cause deterioration in hand function and difficulties in activities of daily living (ADL). ${ }^{1}$ Therefore, it is important to evaluate hand function in clinical practice and in clinical trials. Several instruments have been developed to evaluate hand disability in patients with diseases that affect the hands. ${ }^{2-6}$ Most of the performance tests require special equipment, training, and/or may be too time-consuming. The Grip Ability Test (GAT) is a quick and easy test of hand function specifically designed for individuals with RA to evaluate the outcome of hand training programs. It has been demonstrated to be valid, reliable, and sensitive to change by the developers of the test. ${ }^{6}$

Received: February 20, 2014 Accepted: February 25, 2014

Correspondence: Çiğdem Bircan, M.D. Dokuz Eylül Üniversitesi Tıp Fakültesi Fiziksel Tıp ve Rehabilitasyon Anabilim Dalı, 35340 Balçova, İzmir, Turkey.

Tel: +90 232 - 4123960 e-mail: cigdem.bircan@deu.edu.tr

(2014 Turkish League Against Rheumatism. All rights reserved. 
However, its relationship with disease activity, hand-specific self-report questionnaires, and hand deformities in RA patients has not been studied in detail. The aim of this study was to investigate the relationship between the GAT and disease activity, and hand-specific self-report questionnaires in patients with RA.

\section{PATIENTS AND METHODS}

Sixty-five patients (55 females, 10 males; mean age of $55 \pm 11$ years; range 24 to 74 years) with RA, according to the American College of Rheumatology/European League Against Rheumatism criteria, ${ }^{7}$ were recruited in this study during the period between March and June 2013. Exclusion criteria were additional diagnoses which might affect nerve and muscle function or mental problems. The study protocol was approved by the Dokuz Eylul University Ethics Committee for Noninvasive Clinical Research. Informed consents were obtained from all patients.

Demographic and clinical data including age, sex, hand dominance, disease duration, and duration of morning stiffness were obtained. A physical examination was performed and the number of tender joints and the number of swollen joints were recorded. The hands were evaluated to find out the presence and type of deformities. Laboratory tests which measure disease activity including erythrocyte sedimentation rate (ESR, $\mathrm{mm} / \mathrm{h}$ ), and C-reactive protein (CRP, mg/dl) were obtained on the same day of the recording session.

Hand pain at rest and during ADL was evaluated separately on a $100 \mathrm{~mm}$ visual analog scale (VAS). Stiffness in hands was also rated by the patients on a 0-100 mm VAS (0 representing "no stiffness" and 100 "maximal stiffness).

A Jamar dynamometer (Sammons Preston, Inc., Bolingbrook, IL, USA) was used to evaluate the grip strength. Measurement was performed with the patient sitting in a standardized position and elbow flexed at a $90^{\circ}$ angle. Three trials were conducted and the mean value was calculated for each hand. The values were recorded in kilograms.

Composite motion of finger flexion was assessed by asking the patient to make a fist, and the distance from the distal palmar crease to the tip of the fingers was measured by a ruler for each finger. The sum of flexion deficits in fingers II-V (in $\mathrm{mm}$ ) was used as measures. ${ }^{6}$

Disease activity was assessed according to the Disease Activity Score 28 (DAS28). This is a composite index based on the number of tender and swollen joints, patient's global assessment (VAS) of disease activity, and an acute phase reactant. ${ }^{8}$ We used CRP values to calculate the DAS28.

Disability was evaluated by the Health Assessment Questionnaire (HAQ), ${ }^{9}$ Arthritis Impact Measurement Scale 2 (AIMS2) hand/finger function subscale, ${ }^{10}$ and Duruoz Hand Index (DHI). ${ }^{11}$

The HAQ is a self-administered questionnaire which consists of 20 questions in eight categories of functioning. The total score ranges between 0 and 3, with higher scores indicating greater disability. The Turkish version of the HAQ, which has been reported to be valid and reliable, was used in the present study. ${ }^{12}$

The AIMS2 is a disease-specific 78-item questionnaire which measures many aspects of health status including physical function, psychosocial aspects, and pain in 12 scales. The score ranges from 0 to 10 (10 corresponds to worst possible health) for each subscale. The hand and finger function subscale of the validated Turkish version of AIMS2 was used in this study. ${ }^{13}$

Duruoz Hand Index is a questionnaire which consists of 18 questions evaluating hand function in five subcategories: kitchen, dressing, hygiene, office, and other. Patient rates the amount of difficulty during the activities on a scale from 0 to 5 , with 0 corresponding to "no difficulty" and 5 corresponding to "impossible to do". The total score ranges between 0 and 90 . The questionnaire was developed to evaluate hand function in RA patients ${ }^{11}$ and the Turkish version was also found valid and reliable in patients with several other diseases including stroke, traumatic hand injury, and diabetes. ${ }^{14-16}$

The GAT is a performance-based test of hand function specifically developed for subjects with RA. It consists of three items which represents different grip types used in daily life:

1. Put a $25 \mathrm{~cm}$ of Tubigrip elasticized tubular bandage (Seton, Healthcare Group Plc, Oldham,UK) over the non-dominant hand [Size D 
(7.5 cm width) for women and size F (10 cm width) for men],

2. Pick up a metal paper clip $(30 \times 10 \mathrm{~mm})$ from the table with the dominant hand and place it on a letter envelope $(11.5 \times 16 \mathrm{~cm})$, and

3. Lift a one liter jug of water with the dominant hand and fill a cup (size $200 \mathrm{ml}$ ) with water.

Time needed to perform each item is recorded in seconds and a correction factor of 1.8 is used for items (1) and (2). The score ranges between 10 and 276 , with a high score corresponding to decreased hand function. If the patient is unable to perform an item in 60s, time is recorded as 60s for that item. Mean score for healthy controls was found 16.5s (range 11.0-20.0). ${ }^{6}$

\section{Statistical analysis}

Statistical analysis was performed using the SPSS version 15.0 for Windows software program (SPSS Inc., Chicago, IL, USA). Non-parametric tests were used as most of the dependent variables were not normally distributed (ShapiroWilk test). Correlations between different variables were analyzed by Spearman rank correlation. Differences between subgroups were analyzed using the Mann-Whitney $U$ test. A $p$ value of $<0.05$ was considered statistically significant.

\section{RESULTS}

The mean disease duration was $10.2 \pm 8.2$ years (range 1-42 years). Sixty-three patients (97\%) were right-handed, and two patients (3\%) were left-handed. Duration of morning stiffness was
$39 \pm 67$ minutes (range 0-240 minutes). Table 1 shows clinical parameters, disability and GAT scores of the patients.

At least one hand deformity was found in 14 patients (21.5\%). Table 2 shows the number of patients with different types of hand deformities. The total number of hand deformities in a patient ranged from 0 to 8 .

Correlations between the GAT score and the study parameters are given in Table 3 . Significant positive correlations were found between the GAT score and the duration of morning stiffness, VAS-pain during ADL, VAS-stiffness, finger flexion deficit of dominant hand, DAS28, HAQ, AIMS2 hand/finger function subscale, and DHI, $(r=0.261$ to $0.639, p<0.05)$. Significant negative correlations were found between the GAT score and the dominant $(r=-0.505, p<0.001)$ and nondominant hand $(r=-0.399, p=0.001)$ grip strength. No significant correlations were found between the GAT and the duration of disease, and VAS-pain at rest.

When patients with and without deformities were compared, patients with deformities had a longer disease duration and lower dominant hand grip strength $(p=0.03$ and $p=0.01$, respectively) while the GAT scores did not differ significantly ( $\mathrm{p}>0.05)$.

When women and men were compared with regard to study parameters, men had a greater grip strength in both the dominant and non-dominant hand $(p=0.009, p=0.014$, respectively). There were no significant differences between the GAT scores of women and men ( $p>0.05)$.

Table 1. Clinical parameters, disability and Grip Ability Test scores of the patients

\begin{tabular}{lccc}
\hline & Mean \pm SD & Median & Range \\
\hline Visual analog scale pain-rest & $22.8 \pm 24.8$ & 10 & $0-90$ \\
Visual analog scale pain-activities of daily living & $41.3 \pm 29.2$ & 50 & $0-100$ \\
Visual analog scale stiffness & $22.7 \pm 28.6$ & 10 & $0-90$ \\
Grip strength, dominant hand (kg) & $20.4 \pm 7.9$ & 18 & $7-40.6$ \\
Grip strength, nondominant hand (kg) & $19.1 \pm 7.9$ & 18.3 & $4-38.6$ \\
Flexion deficit, dominant hand (mm) & $3.9 \pm 13.1$ & 0 & $0-90$ \\
Flexion deficit, nondominant hand (mm) & $1.2 \pm 4.9$ & 0 & $0-30$ \\
Disease Activity Score 28 & $2.9 \pm 1.1$ & 2.7 & $0.96-5.25$ \\
Health Assessment Questionnaire & $0.6 \pm 0.6$ & 0.5 & $0-2.3$ \\
AIMS2 hand/finger function & $3.1 \pm 2.2$ & 3 & $0-8$ \\
Duruöz Hand Index & $11.6 \pm 13.2$ & 6 & $0-47$ \\
Grip Ability Test & $31.1 \pm 11.4$ & 27.2 & $17.4-69.6$ \\
\hline SD: Standard deviation; AIMS2: Arthritis Impact Measurement Scale 2. & & & \\
\hline
\end{tabular}


Table 2. Number of patients with hand deformities

\begin{tabular}{lcccc}
\hline Hand deformity & Right hand & Left hand & Both hands & Total \\
\hline Swan neck & 2 & 2 & 3 & 7 \\
Boutonniere & 1 & 1 & 3 & 2 \\
Z deformity & 1 & 1 & 5 \\
Ulnar deviation of the metacarpophalangeal joint & 1 & 1 & 3 & 6 \\
Volar subluxation of the metacarpophalangeal joint & 1 & & 4 \\
\hline
\end{tabular}

\section{DISCUSSION}

Rheumatoid arthritis is a systemic inflammatory disease in which most of the patients suffer from involvement of the hands. ${ }^{1}$ Traditionally, hand assessment in RA patients includes measures of impairment such as pain, stiffness, swelling, range of motion, and deformities. Although these measures of impairment provide information about the clinical status of patient and may give some opinion about hand function, they may not exactly demonstrate the amount of difficulty that the patients have in daily life. Therefore, a comprehensive assessment of hand function should include tasks simulating everyday functional activities. ${ }^{17}$ The GAT is an ADL-based hand function test which was developed by Dellhag and Bjelle from the more general Grip Function Test by Sollerman. It was designed for individuals with RA to evaluate the outcome of hand training programs. ${ }^{6}$ In this study, we evaluated the relationship between the GAT and disease activity, and hand-specific self-report questionnaires in patients with RA, and found acceptable degrees of correlation.

Table 3. Correlations between Grip Ability Test and clinical parameters, disease activity and subjective disability measures

\begin{tabular}{lc}
\hline & Grip Ability Test $(\mathrm{r})$ \\
\hline Disease duration & 0.063 \\
Duration of morning stiffness & $0.331^{* *}$ \\
VAS-pain-rest & 0.006 \\
VAS-pain-ADL & $0.261^{*}$ \\
VAS-stiffness & $0.442^{* *}$ \\
Grip strength, DH & $-0.505^{* * *}$ \\
Grip strength, NDH & $-0.399^{* *}$ \\
Flexion deficit, DH & $0.267^{* *}$ \\
Flexion deficit, NDH & 0.105 \\
DAS28 & $0.351^{* * *}$ \\
HAQ & $0.639^{* *}$ \\
AIMS2 hand/finger function & $0.603^{* *}$ \\
Duruöz Hand Index & $0.617^{* *}$ \\
\hline VAS: Visual analog scale; ADL: Activities of daily living; DH: Dominant hand; \\
NDH: Nondominant hand; DAS: Disease Activity Score; HAQ: Health Assessment \\
Questionnaire; AIMS2: Arthritis Impact Measurement Scale 2; ${ }^{*} \mathrm{p}<0.05 ;{ }^{* *} \mathrm{p}<0.01$. \\
\hline
\end{tabular}

In the present study, the GAT had the strongest correlation with the self-report disability questionnaires. The GAT scores correlated moderately with both patient-perceived hand disability (DHI and hand/finger subscale of AIMS2) and general disability (HAQ). Dellhag and Bjelle $^{6}$ reported significant correlation between the GAT and the HAQ; however, they did not include a questionnaire specific to hand in their study. Eberhardt et al. ${ }^{18}$ also reported that GAT was significantly related to HAQ in RA patients in their study, however, their study did not also include any hand-specific questionnaire. The correlation between the GAT and the HAQ, which is a generalized measure of disability, suggests that hand dysfunction has a considerable impact on general disability. Adams et al. ${ }^{19}$ explored the relationship between Disability of the Arm, Shoulder and Hand (DASH), GAT and several measures of hand impairment in patients with early RA. They found a significant correlation between the DASH and the GAT.

We assessed the intensity of hand pain during the day both at rest and during ADL. Pain at rest did not correlate with GAT scores; however, there was a weak correlation between GAT and pain during ADL. Dellhag and Bjelle ${ }^{6}$ measured the intensity of hand pain in two different conditions: with non-resisted motion and with resisted motion during the performance of GAT items. Both were found to correlate significantly with the total GAT score.

The intensity of stiffness in hands and the duration of morning stiffness were both correlated with GAT in our study. Dellhag and Bjelle 6 also reported a significant correlation between hand stiffness and GAT. In another study, Vlieland et al. ${ }^{20}$ investigated the relationship between hand function and clinical variables. Hand function assessment included Jebsen test and the authors reported a significant correlation between stiffness of the hands and hand dysfunction. 
Muscle strength has been reported to be lower in RA patients compared to healthy controls. ${ }^{21,22}$ Significant correlations between grip strength and general disability, ${ }^{23,24}$ as well as hand dysfunction, ${ }^{20,24}$ have been found in studies where hand function was evaluated by methods other than GAT. In our study, GAT correlated significantly with both dominant and non-dominant hand grip strength. Dellhag and Bjelle ${ }^{6}$ measured grip strength of only the dominant hand, and reported a significant correlation with GAT. In three other studies, significant correlations between grip force and the GAT were found. Two of these studies were composed of only early RA patients, ${ }^{19,25}$ and the third one $e^{18}$ included only patients with highly active disease with most of them having severe hand dysfunction.

We found a weak correlation between DAS28 and hand disability evaluated by the GAT. Several previous studies have reported weak to moderate correlations between disease activity and hand or upper extremity disability; however, hand disability was assessed with selfreport questionnaires, not by GAT, in these studies. ${ }^{24,26-29}$ In a study by Eberhardt et al., ${ }^{18}$ in which GAT was used to evaluate hand disability, GAT was not significantly associated with disease activity. The authors considered that this might have resulted from the fact that most of their patients already had severe hand dysfunction. Their study group was composed of patients all receiving anti-tumor necrosis factor (anti-TNF) therapy with high disease activity. Our study population included patients in remission as well as patients with low, moderate or high disease activity, although the number of patients with high disease activity was relatively low. Weak correlations between disease activity and disability measures suggest that evaluation of hand disability may add important information to evaluation with traditional assessment methods.

Hand deformity is one of the main characteristics of RA. Most common deformities are buttonhole deformity, swan neck deformity, and ulnar deviation of the metacarpophalangeal joints. Different deformities may develop simultaneously in the same hand. Johnsson et al. ${ }^{30}$ observed the development of hand deformities in early RA patients in a prospective study. The results showed that hand deformities considerably affected both hand function and overall function.
Taştekin et al. ${ }^{31}$ reported that patients with ulnar deviation had higher DHI scores and lower grip strength. Vliet Vlieland et al. ${ }^{20}$ reported that ulnar deviation and $\mathrm{Z}$ deformity were important determinants of hand function. Adams et al. ${ }^{19}$ found a weak to moderate correlation between the degree of ulnar deviation and GAT in early RA patients. In our study, grip strength of patients with deformities was lower than that of patients without deformities, but the GAT scores did not differ significantly. Discrepancies between studies may result from the differences between assessment methods and study populations. The prevalence of hand deformities was generally low in our study. In addition, we could not explore the relationship between the GAT scores and different types of deformity, since the number of patients in each subgroup of deformity was quite low.

In our study, finger flexion deficit of the dominant hand correlated significantly with GAT. This result is in line with the finding of Dellhag and Bjelle. ${ }^{6}$ In addition, they used the hand and wrist items of the Keitel Functional Test, which assesses joint limitations, and reported a significant correlation with GAT. Three studies evaluated range of motion of the hand joints by Signals of Functional Impairment, in which the patient performs opening grip, pinch grip, and thumb opposition in addition to finger flexion. ${ }^{18,25,32}$ All reported significant correlations between Signals of Functional Impairment and GAT.

There are several limitations of this study. The number of patients with high disease activity in our study population was low, as assessed by the DAS28. In addition, the prevalence of deformities was lower than in most of the studies in the literature. It would have been optimal, if the study population had been more heterogeneous with regard to disease activity and hand deformities.

In conclusion, weak to moderate correlations were found between the GAT and disease activity, and hand-specific self-report questionnaires in patients with RA. An evaluation of patients with a performance-based test such as GAT as well as clinical and laboratory assessments may provide important additional information about the patients' hand disability. 


\section{Declaration of conflicting interests}

The authors declared no conflicts of interest with respect to the authorship and/or publication of this article.

\section{Funding}

The authors received no financial support for the research and/or authorship of this article.

\section{REFERENCES}

1. Gordon DA, Hastings DE. Rheumatoid arthritis. Clinical features of early, progressive and late disease. In: Klippel JH, Dieppe PA, editors. Rheumatology. 2nd ed. London: Mosby; 2000. p. 5.3.1-14.

2. Jebsen RH, Taylor N, Trieschmann RB, Trotter MJ, Howard LA. An objective and standardized test of hand function. Arch Phys Med Rehabil 1969;50:311-9.

3. Backman C, Mackie H. Arthritis hand function test: development of a standardized assessment tool. Occup Ther J Res 1991;11:245-56.

4. van Lankveld W, van't Pad Bosch P, Bakker J, Terwindt S, Franssen M, van Riel P. Sequential occupational dexterity assessment (SODA): a new test to measure hand disability. J Hand Ther 1996;9:27-32.

5. Sollerman C, Ejeskär A. Sollerman hand function test. A standardised method and its use in tetraplegic patients. Scand J Plast Reconstr Surg Hand Surg 1995;29:167-76.

6. Dellhag B, Bjelle A. A Grip Ability Test for use in rheumatology practice. $\mathrm{J}$ Rheumatol 1995;22:1559-65.

7. Aletaha D, Neogi T, Silman AJ, Funovits J, Felson DT, Bingham CO 3rd, et al. 2010 Rheumatoid arthritis classification criteria: an American College of Rheumatology/European League Against Rheumatism collaborative initiative. Arthritis Rheum 2010;62:2569-81.

8. Prevoo ML, van't Hof MA, Kuper HH, van Leeuwen MA, van de Putte LB, van Riel PL. Modified disease activity scores that include twenty-eight-joint counts. Development and validation in a prospective longitudinal study of patients with rheumatoid arthritis. Arthritis Rheum 1995;38:44-8.

9. Fries JF, Spitz P, Kraines RG, Holman HR. Measurement of patient outcome in arthritis. Arthritis Rheum 1980;23:137-45.

10. Meenan RF, Mason JH, Anderson JJ, Guccione AA, Kazis LE. AIMS2. The content and properties of a revised and expanded Arthritis Impact Measurement Scales Health Status Questionnaire. Arthritis Rheum 1992;35:1-10.

11. Duruöz MT, Poiraudeau S, Fermanian J, Menkes CJ, Amor B, Dougados M, et al. Development and validation of a rheumatoid hand functional disability scale that assesses functional handicap. J Rheumatol 1996;23:1167-72.
12. Küçükdeveci AA, Sahin H, Ataman S, Griffiths B, Tennant A. Issues in cross-cultural validity: example from the adaptation, reliability, and validity testing of a Turkish version of the Stanford Health Assessment Questionnaire. Arthritis Rheum 2004;51:14-9.

13. Atamaz F, Hepguler S, Oncu J. Translation and validation of the Turkish version of the arthritis impact measurement scales 2 in patients with knee osteoarthritis. J Rheumatol 2005;32:1331-6.

14. Sezer N, Yavuzer G, Sivrioglu K, Basaran P, Koseoglu BF. Clinimetric properties of the Duruoz hand index in patients with stroke. Arch Phys Med Rehabil 2007;88:309-14.

15. Turan Y, Duruöz MT, Aksakalli E, Gürgan A. Validation of Duruöz Hand Index for diabetic hand dysfunction. J Investig Med 2009;57:887-91.

16. Erçalik T, Şahin F, Erçalik C, Doğu B, Dalgiç S, Kuran B. Psychometric characteristics of Duruoz Hand Index in patients with traumatic hand flexor tendon injuries. Disabil Rehabil 2011;33:1521-7.

17. McPhee SD. Functional hand evaluations: a review. Am J Occup Ther 1987;41:158-63.

18. Eberhardt K, Sandqvist G, Geborek P. Hand function tests are important and sensitive tools for assessment of treatment response in patients with rheumatoid arthritis. Scand J Rheumatol 2008;37:109-12.

19. Adams J, Burridge J, Mullee M, Hammond A, Cooper C. Correlation between upper limb functional ability and structural hand impairment in an early rheumatoid population. Clin Rehabil 2004;18:405-13.

20. Vliet Vlieland TP, van der Wijk TP, Jolie IM, Zwinderman AH, Hazes JM. Determinants of hand function in patients with rheumatoid arthritis. J Rheumatol 1996;23:835-40.

21. Ekdahl C, Broman G. Muscle strength, endurance, and aerobic capacity in rheumatoid arthritis: a comparative study with healthy subjects. Ann Rheum Dis 1992;51:35-40.

22. Häkkinen A, Hannonen P, Häkkinen K. Muscle strength in healthy people and in patients suffering from recent-onset inflammatory arthritis. $\mathrm{Br} \mathrm{J}$ Rheumatol 1995;34:355-60.

23. Häkkinen A, Kautiainen $\mathrm{H}$, Hannonen $\mathrm{P}$, Ylinen J, Mäkinen $\mathrm{H}$, Sokka T. Muscle strength, pain, and disease activity explain individual subdimensions of the Health Assessment Questionnaire disability index, especially in women with rheumatoid arthritis. Ann Rheum Dis 2006;65:30-4.

24. Dedeoğlu M, Gafuroğlu Ü, Yllmaz Ö, Bodur H. The relationship between hand grip and pinch grip strengths and disease activitiy, articular damage, pain, and disability in patients with rheumatoid arthritis. Turk J Rheumatol 2013;28:69-77.

25. Björk M, Thyberg I, Haglund L, Skogh T. Hand function in women and men with early rheumatoid arthritis. A prospective study over three years (the Swedish TIRA project). Scand J Rheumatol 2006;35:15-9. 
26. Bodur H, Yilmaz O, Keskin D. Hand disability and related variables in patients with rheumatoid arthritis. Rheumatol Int 2006;26:541-4.

27. Aktekin LA, Eser F, Başkan BM, Sivas F, Malhan S, Öksüz E, et al. Disability of Arm Shoulder and Hand Questionnaire in rheumatoid arthritis patients: relationship with disease activity, HAQ, SF-36. Rheumatol Int 2011;31:823-6.

28. Birtane M, Kabayel DD, Uzunca K, Unlu E, Tastekin $\mathrm{N}$. The relation of hand functions with radiological damage and disease activity in rheumatoid arthritis. Rheumatol Int 2008;28:407-12.

29. Raven EE, Haverkamp D, Sierevelt IN, van Montfoort DO, Pöll RG, Blankevoort L, et al. Construct validity and reliability of the disability of arm, shoulder and hand questionnaire for upper extremity complaints in rheumatoid arthritis. J Rheumatol 2008;35:2334-8.

30. Johnsson PM, Eberhardt K. Hand deformities are important signs of disease severity in patients with early rheumatoid arthritis. Rheumatology (Oxford) 2009;48:1398-401.

31. Taştekin N, Uzunca K, Birtane M, Kabayel DD, Öztürk G. Romatoid artrit'li hastalarda, el eklemlerindeki hareket açıklığı ve el kavrama kuvvetlerinin hastalık aktivasyonu, el fonksiyonları ve özürlülük ile ilişkisi. Turk J Rheumatol 2006;21:13-7.

32. Sandqvist G, Johnsson PM, Sturesson AL, Tägil M, Geborek P. Measures and time points relevant for postsurgical follow-up in patients with inflammatory arthritis: a pilot study. BMC Musculoskelet Disord 2009;10:50. 